\title{
The Influence of Coupling Misalignment on Dynamic Characteristics of Helical Gear System
}

\author{
Jian Xu \\ Institute of Thermal Science and Power Engineering \\ Zhejiang University, No.38, Zheda Rd \\ Zhejiang 310000, China
}

Shuiguang Tong

\author{
Department of Mechanical Engineering \\ Zhejiang University, No.38, Zheda Rd \\ Zhejiang 310000, China
}

\author{
Feiyun Cong* \\ Department of Mechanical Engineering \\ Zhejiang University, No.38, Zheda Rd \\ Zhejiang 310000, China \\ *Corresponding author
}

\section{Yi Zhou}

Institute of Thermal Science and Power Engineering Zhejiang University, No.38, Zheda Rd Zhejiang 310000, China

\begin{abstract}
The shaft misalignment usually causes the severe vibration of rotating machine. In this paper, a three-dimensional dynamic model of a coupled gear-rotor system is developed to simulate this phenomenon. The numerical simulation of the dynamic characteristics is performed to analyze the effects of both internal gear meshing and external shaft misalignment related dynamic excitations on the gearbox transmission response. This study provides useful theoretical guideline to the helical gear system design.
\end{abstract}

Keywords-helical gear; dynamic model;coupling misalignment; vibration analysis

\section{INTRODUCTION}

The gear train system are one of the most essential components in industrial machinery due to its high efficiency, tight structure, stable speed ratio and so on[1]. Severe vibration control of gear train system are important to machine's safe operation. Shaft misalignment is a condition in which the shaft of the driving machine and the shaft of the driven machine are not on the same center line, which will cause the abnormal vibration of the connected equipment, such as gearbox. There are two typical types of misalignment, angular misalignment and parallel misalignment[2]. When the connected two shafts have different angular orientations, the angular misalignment occurs. For the parallel misalignment, the connected shafts have the same angular orientations, but center lines are separated from each other. The existence of shaft misalignment will influence the dynamic characteristic of the gear mesh response and need to further analysis.

During the recent decades, several research works for shaft misalignment has been represented. Many researchers have proposed theoretical models to represent this phenomenon through vibratory analysis. Xu and Marangoni [3, 4]pursued a vibration analysis based on a theoretical model and its validation. They figured out that shaft misalignment tends to show up as a series harmonics of the shaft rotating speed. AlHussain and Redmond[5] studied the dynamic response of two rotors connected by rigid and flexible mechanical coupling with parallel misalignment and angular misalignment. Lees has studied the vibration response of misalignment fault in the rigid connected rotor system. Some experiments were also achieved to research the phenomenon of misalignment. Dewell and Mitchell[6] analyzed the vibration frequencies for a misaligned metallic disk flexible coupling. However, there are rarely researches on the influence of the misalignment to helical gear train system. Do some researches on the impact of the misalignment to gear train system can improve the precision of the gear transmission.

In this paper, the influence of the combination both of angle and parallel misalignments to the dynamic characteristics of helical gear system has been studied. The dynamics simulation model was used to study the characteristics and influencing factors of gearbox vibration which generated by the compound misalignments.

\section{GEARSYSTEM Model With SHAFT MisALIGNMENT}

FIGURE. 1 represents the dynamic diagram of a helical gear train system with shaft misalignments. This misalignment combines both angular misalignment and parallel misalignment.

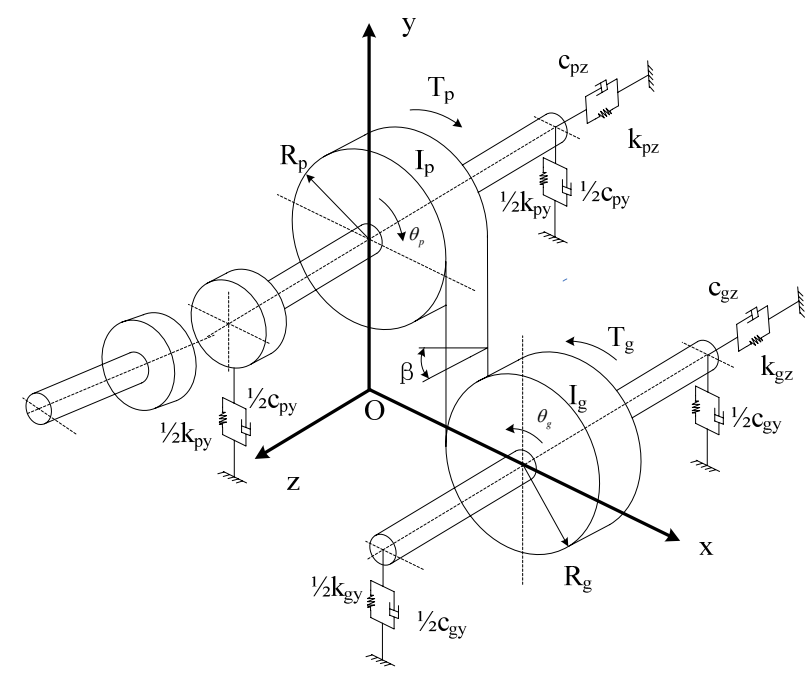

FIGURE I. GEAR TRAIN MODEL WITH MISALIGNMENT 


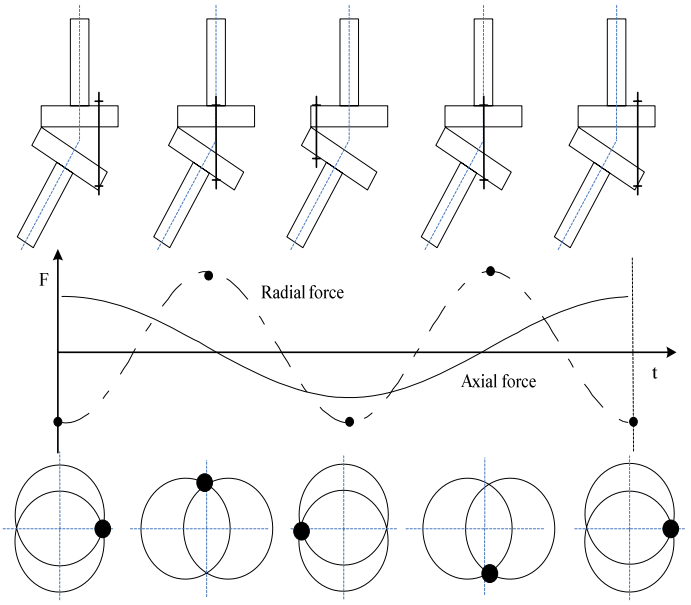

FIGURE II. THE DIAGRAM OF MISALIGNMENT FORCE

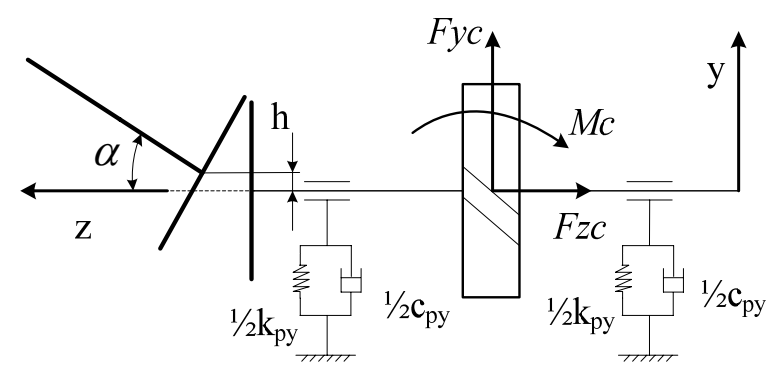

FIGURE III. THE DIAGRAM OF FORCE ANALYSIS

\section{A. The Calculation of Misalignment Force}

The mechanism model taken in this paper contains a helical gear pair and rotor shaft with compound misalignment. FIGURE. 2 illustrates the change regulation of additional forces caused by shaft misalignment. According to FIGURE.2, the axial force has the same frequency with the shaft running speed, and the frequency of radial force is as twice as the shaft rotating frequency. Mathematically, these additional force can be expressed as follows:

$$
\begin{aligned}
& F_{C y}(t)=F r \times \cos \left(2 \times 2 \pi f_{r} \times t\right) \\
& F_{C Z}(t)=F a \times \cos \left(2 \pi f_{r} \times t\right)
\end{aligned}
$$

where the $F_{c y}$ and $F_{c y}$ indicates the radial force and axial force respectively. The $f_{r}$ is the rotating frequency of the driven shaft. The coefficients $F_{r}$ and $F_{a}$ are related to the deflection angle, the parallel displacement, the stiffness of coupling and the shaft torque. To simplify the calculation process, the force acting on the coupling is equivalent to the force on the driven gear. FIGURE. 3 is the schematic diagram of equivalent result.

\section{B. The Mathematical Model}

The proposed dynamic model of the helical gear pair is shown in FIGURE.1, which shows the driving gear (subscript g) meshing with the driven gear (subscript p). In this study, we take into account the dynamic characteristics and vibration responses of this gear pair in three dimensions. The following assumptions are made in the mathematical model[7].
1. The deflection of the gear shaft is neglected, because the length of the shaft is little.

2. Shaft mass and inertia are neglected, and the helical gear backlash is also neglected.

3. Gear pair meshing flexibility and other parts flexibility are included in a linear spring.

4. The gear meshing stiffness is time-varying, and the support stiffness is constant.

5. Tooth friction and swing vibration motion are not concerned in this dynamic model.

According to the Newton's law and Alembert's principle[8], the dynamic model coupled flexional, torsional and axial motion of a helical gear pair shown in FIGURE. 2 can be expressed as

$$
\begin{aligned}
& m_{g} y_{g}+c_{g y} y_{g}+k_{g y} y_{g}=F_{y} \\
& m_{g} z_{g}+c_{g z} z_{g}+k_{g z} z_{g}=F_{Z} \\
& m_{p} y_{p}+c_{p y} y_{p}+k_{p y} y_{p}=-F_{y}+F_{c y} \\
& m_{p}{ }^{z}{ }^{+}+c_{p z} z_{p}+k_{p z} z_{p}=-F_{Z}-F_{C Z} \\
& I_{g} \dot{\theta}_{g z}=-T_{g}+F_{y} R_{g} \\
& I_{p} \theta_{p z}=T_{p}-F_{y} R_{p} \\
& F_{y}=k_{m y}\left(\overline{y_{p}}-\overline{y_{g}}\right)+c_{m y}\left(\dot{\overline{y_{p}}}-\dot{\overline{y_{g}}}\right) \\
& =\cos \beta\left[k_{m}\left(y_{p}+\theta_{p} R_{p}-y_{g}-\theta_{g} R_{g}\right)+c_{m}\left(y_{p}+\theta_{p} R_{p}-y_{g}-\theta_{g} R_{g}\right)\right] \\
& F_{Z}=k_{m Z}\left(\overline{z_{p}}-\overline{z_{g}}\right)+c_{m z}\left(\dot{\overline{z_{p}}}-\overline{\dot{z_{g}}}\right) \\
& =\sin \beta\left\{\left[k_{m}\left(z_{p}-\tan \beta\left(y_{p}+\theta_{p} R_{p}\right)-z_{g}+\tan \beta\left(y_{g}+\theta_{g} R_{g}\right)\right]\right.\right. \\
& \left.+c_{m}\left[z_{p}-\tan \beta\left(y_{p}+\dot{\theta}_{p} R_{p}\right)-\dot{z}_{g}+\tan \beta\left(\dot{y}_{g}+\dot{\theta}_{g} R_{g}\right)\right]\right\}
\end{aligned}
$$

Where, $R_{i}(i=g, p$ )represent the base radii of driving gear and driven gear, respectively. $m_{i}(i=g, p)$ indicates the equivalent mass of driving gear and driven gear, respectively. $I_{i}$ $(i=g, p)$ is the moment of inertia of driving gear and driven gear, respectively. $T_{i}(i=g, p)$ represent the driving torque and loading torque, respectively. $k_{i j}(i=g, p$ and $j=y, z)$ is the supporting stiffness of bearings of driving gear and driven gear in the $y$ and $z$ direction , respectively. $c_{i j}(i=g, p$ and $j=y, z)$ indicates the supporting gear damping of driving gear and driven gear in the $y$ and $z$ direction , respectively. To simplify the calculation process, the mesh stiffness of this gear pair in the $y$ and $z$ direction are defined as follows

$$
\begin{array}{ll}
k_{m z}=k_{m} \sin \beta & k_{m y}=k_{m} \cos \beta \\
k_{m z}=k_{m} \sin \beta & k_{m y}=k_{m} \cos \beta \\
c_{m z}=c_{m} \sin \beta & c_{m y}=c_{m} \cos \beta \\
c_{m z}=c_{m} \sin \beta & c_{m y}=c_{m} \cos \beta
\end{array}
$$




\section{The Calculation of Mesh Stiffness}

The gear mesh stiffness fluctuation as a form of parametric excitation, is caused by the time-varying of the composite mesh stiffness due to the internal multi-tooth gear engagement process[9]. When the gear pair engages to transmit motion and force, the number of contacted teeth varies in a periodic discrete form. Additionally, the effective mesh stiffness for each contacted pair of teeth varies periodically as the pair rolls through one tooth to another mesh cycle. This is partly due to the change in the position of the contact lines on the tooth profile surface. According to [9], the time-varying behavior of a single contact line of a helical gear tooth pair can be expressed as $l_{\mathrm{i}}(t)$. Then by superposition of all the tooth pairs in contact at any given time, the total mesh stiffness can be expressed as $K_{m}(t)$.

$$
\begin{aligned}
& l_{i}(t)=a_{0} / 2+\sum_{n=1}^{\infty}\left[a_{n} \cos \left(\frac{2 \pi n t}{T_{Z}}\right)+b_{n} \cos \left(\frac{2 \pi n t}{T_{Z}}\right)\right] \\
& K_{m}(t)=k_{m} \times \sum_{i=1}^{p} l_{i}\left[t-i \frac{T_{Z}}{(\varepsilon+1)}\right]
\end{aligned}
$$

where $p$ is the number of gear teeth pairs in contact and $i$ is the serial number of contact lines. $\mathrm{T}_{\mathrm{z}}$ indicates the gear meshing period. $\varepsilon_{\text {is }}$ the total contact ratio of this gear pair. The timevarying meshing stiffness is shown in FIGURE. 4.

The equation of motion is given in the matrix form as

$$
[M]\{\ddot{X}\}+[C]\{\dot{X}\}+K_{m}(t)\{X\}=\{P(t)\}
$$

where $\mathrm{M}$ is the mass matrix, $\mathrm{C}$ is the damping matrix, $\mathrm{Km}(\mathrm{t})$ indicates the stiffness matrix, $\mathrm{X}$ is the vector of the displacement , and $\mathrm{P}(\mathrm{t})$ is the vector of the load. In this study, we used the Newmark time integration method to solve the (5). The Newmark method is a generalization of the linear acceleration method[10]. This latter method assumes that the acceleration varies linearly within the interval $(\mathrm{t}+\Delta \mathrm{t})$. this give

$$
\begin{aligned}
& \left\{\ddot{x}_{n}\right\}=\left\{\ddot{x}_{t}\right\}+\frac{1}{\Delta t}\left(\left\{\ddot{x}_{t+\Delta t}\right\}-\ddot{x}_{t}\right) ; \\
& \left\{\ddot{x}_{t+\Delta t}\right\}=\left\{\dot{x}_{t}\right\}+\left[(1-\delta)\left\{\dot{x}_{t}\right\}+\delta\left\{x_{t+\Delta t}\right\}\right] \Delta t ; \\
& \left\{x_{t+\Delta t}\right\}=\left\{x_{t}\right\}+\left\{\dot{x}_{t}\right\} \Delta t+\left[(1 / 2-\beta)\left\{\ddot{x}_{t}\right\}+\beta\left\{x_{t+\Delta t}\right\}\right] \Delta t^{2} .
\end{aligned}
$$

The response at time $\mathrm{t}+\Delta \mathrm{t}$ is required by evaluating the equation of motion at time $\mathrm{t}+\Delta \mathrm{t}$. Therefore, the Newmark method is an implicit method. The main parameters of this gear train system is represented in Table 1.

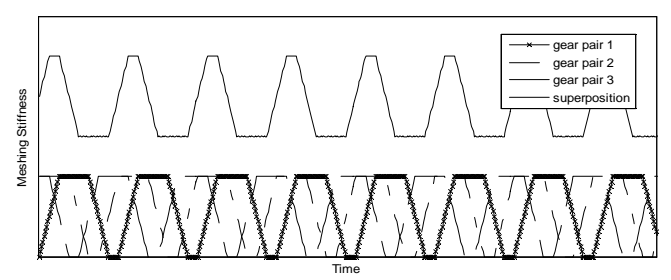

FIGURE IV. INPUT TIME-VARYING MESHING SFIFFNESS
TABLE I. MAIN PARAMETERS OF THE GEARBOX SYSTEM

\begin{tabular}{|l|c|}
\hline \multicolumn{1}{|c|}{ Parameters of dynamic model } & Value \\
\hline Mass of the driving gear & $1.12 \mathrm{Kg}$ \\
\hline Mass of the driven gear & $7.26 \mathrm{Kg}$ \\
\hline Mass moment of inertia of the driving gear & $8.56 \times 10^{-4} \mathrm{Kg} . \mathrm{m}^{2}$ \\
\hline Mass moment of inertia of the driven gear & $5.39 \times 10^{-2} \mathrm{Kg} \cdot \mathrm{m}^{2}$ \\
\hline Input shaft frequency & $30 \mathrm{~Hz}$ \\
\hline Mesh frequency & $570 \mathrm{~Hz}$ \\
\hline Radial stiffness of the bearing & $6.6 \times 10^{7} \mathrm{~N} / \mathrm{m}$ \\
\hline Damping coefficient of the bearing & $1.8 \times 10^{5} \mathrm{~N} / \mathrm{m}$ \\
\hline Transverse pressure angle & $20^{\circ}$ \\
\hline
\end{tabular}

\section{DynAmic Model Simulation RESUlt}

According to (2) and the main parameters of the gear train system, we simulated the gear pair vibration response with the compound misalignment condition. FIGURE. 5 (A) and (B) represents the displacement in the $y$ direction with and without misalignment, respectively. A quasi-sinusoidal component oscillation around the imposed deviation (radial force). The period of two peaks indicates the half of the running period of the shaft. FIGURE. 5 (C) and (D) represents the displacement in the $\mathrm{z}$ direction with and without misalignment, respectively. The period of two peaks indicates the one running period of the shaft. The displacement waveforms express a possible amplitude modulation phenomenon, and the amplitude of displacement fluctuation are both increased. FIGURE. 6 (A) and (B) displays the spectrum of the acceleration signals in the $\mathrm{y}$ and $\mathrm{z}$ direction with misalignment, respectively. We can find out the double shaft running frequency in y direction and one shaft running frequency in $\mathrm{z}$ direction. Dynamic transmission error (STE) is used to measure the difference between actual positional of gear with ideal positioning and it is measured by vibration displacement in meshing line. The STE can be defined as follows

$$
\text { error }=R_{g} * y_{g}-R_{p} * y_{p}
$$

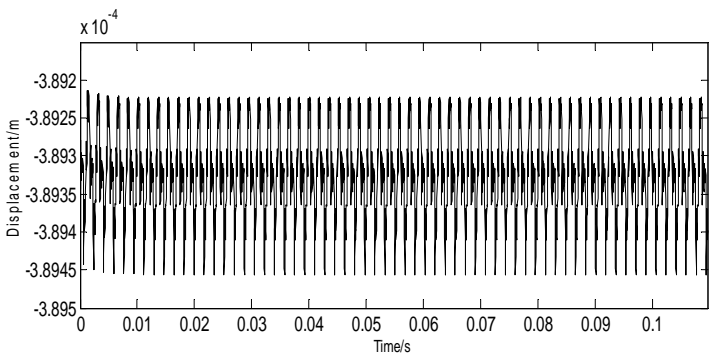

(A) 


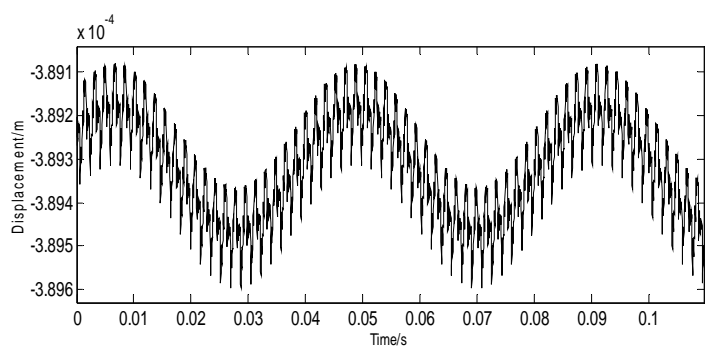

(B)

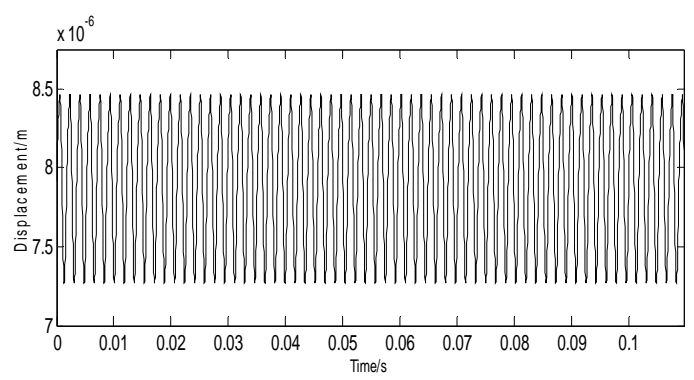

(C)

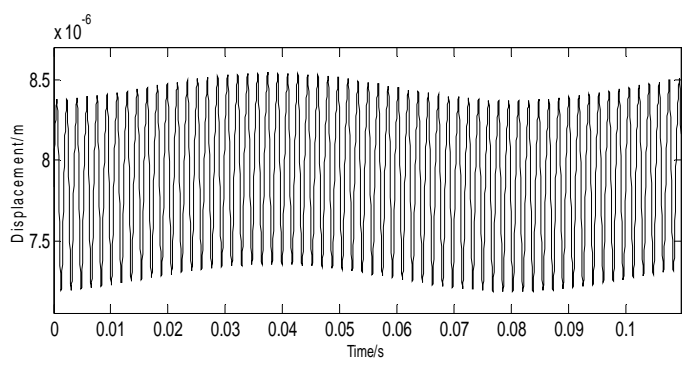

(D)

FIGURE V THE DISPLACEMENT: (A) Y DIRECTION WITHOUT MISALIGNMENT (B) Y DIRECTION WITH MISALIGNMENT (C) Z DIRECTION WITHOUT MISALIGNMENT (D) Z DIRECTION WITH MISALIGNMENT

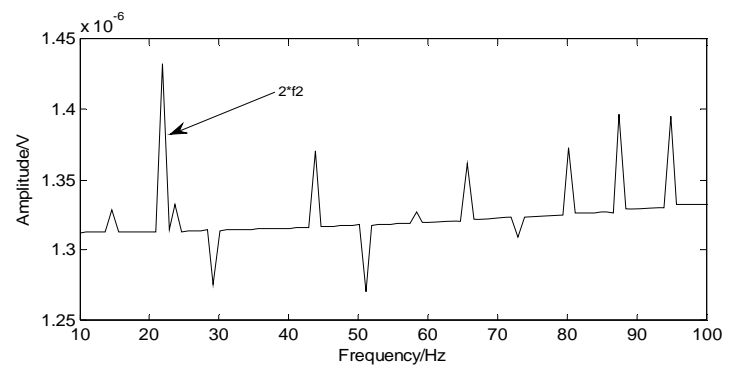

(A)

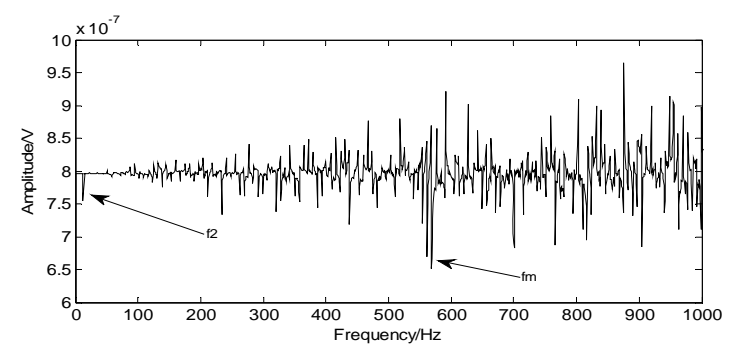

(B)

FIGURE VII. THE DYNAMIC TRANSIMISSION ERROR: (A) Y DIRECTION WITHOUT MISALIGNMENT (B) Y DIRECTION WITH MISALIGNMENT

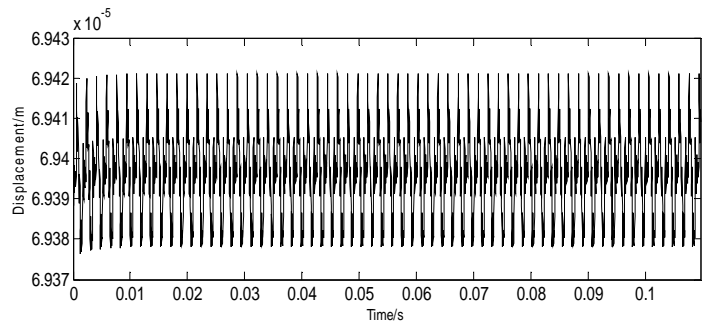

(A)

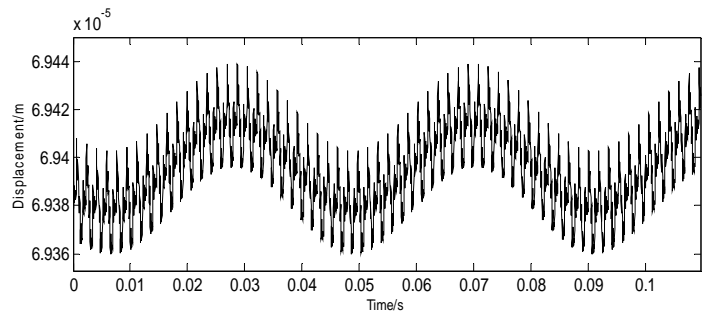

(B)

FIGURE VII. THE DYNAMIC TRANSIMISSION ERROR: (A) Y DIRECTION WITHOUT MISALIGNMENT (B) Y DIRECTION WITH MISALIGNMENT

FIGURE. 7 represents the dynamic transmission error without and with misalignment in the y direction, respectively. Through the comparison, the STE with misalignment is accompanied by the doubled shaft frequency modulation phenomenon with a stronger amplitude volatility.

\section{CONCLUSION}

In this study, we proposed a six-freedom dynamic model to simulate the helical gear train system with misalignment. The simulated vibration signals show that the $y$ direction is essentially characterized by the appearance in the frequency domain of the doubled shaft running frequency, and the $\mathrm{z}$ direction is characterized the shaft running frequency. These two features expressed the actual working condition with misalignment and can be useful in the detection of shaft misalignment in the rotor-gearbox machine diagnosis. 


\section{ACKNOWLEDGMENT}

The research is supported by the National Natural Science Foundation of China (Grant No.51305392), Scientific and Technological Innovation Program of NINGBO (2013B10027) Measurement and Control Aircraft Sea Joint Laboratory Fund (FOM2014OF11).

\section{REFERENCES}

[1] S. Wu, M.J. Zuo, A. Parey, Simulation of spur gear dynamics and estimation of fault growth. Journal of Sound and Vibration, 317 (2008) 608-624

[2] M.A. Hili, T. Fakhfakh, L. Hammami, M. Haddar, Shaft misalignment effect on bearings dynamical behavior. The International Journal of Advanced Manufacturing Technology, 26 (2005) 615-622.

[3] M. Xu, R. Marangoni, Vibration analysis of a motor-flexible couplingrotor system subject to misalignment and unbalance, part i: theoretical model and analysis. Journal of Sound and Vibration, 176 (1994) 663-679.

[4] M. Xu, R. Marangoni, Vibration analysis of a motor-flexible couplingrotor system subject to misalignment and unbalance, part ii: experimental validation. Journal of Sound and Vibration, 176 (1994) 681-691.

[5] K. Al-Hussain, Dynamic stability of two rigid rotors connected by a flexible coupling with angular misalignment. Journal of Sound and Vibration, 266 (2003) 217-234.

[6] L. Mitchell, Detection of a misaligned disk coupling using spectrum analysis. (1984)

[7] J. Zhou, W. Sun, Q. Tao, Gearbox Low-Noise Design Method Based on Panel Acoustic Contribution. Mathematical Problems in Engineering, 2014 (2014)

[8] J. Wei, P. Gao, X. Hu, W. Sun, J. Zeng, Effects of dynamic transmission errors and vibration stability in helical gears. Journal of Mechanical Science and Technology, 28 (2014) 2253-2262.

[9] C. Zhu, B. Lu, C. Song, D. Qin, Dynamic analysis of a heavy duty marine gearbox with gear mesh coupling. Proceedings of the Institution of Mechanical Engineers, Part C: Journal of Mechanical Engineering Science, 223 (2009) 2531-2547.

[10] Y. Gu, G.-R. Liu, A meshless local Petrov-Galerkin (MLPG) method for free and forced vibration analyses for solids. Computational Mechanics, 27 (2001) 188-198. 